\title{
GTO complex as the basis of physical education in DSTU
}

\author{
Nikolay Ryzhkin ${ }^{1}$, Tatiana Tumasyan ${ }^{1}$, Olga Brovashova $^{1,{ }^{*}}$, Elena Nemtseva $^{1}$, and Anna \\ Ivanova $^{1}$ \\ ${ }^{1}$ Don State Technical University, Gagarin sq., 1, Rostov on Don, 344003, Russia
}

\begin{abstract}
Object: search for new methods of influence on improving the quality of work with students in the field of physical culture and sports. The analysis includes data obtained as a result of fulfilling the standards of the GTO complex by students of our university. The peculiarities of the fulfillment of various standards included in the VI stage of the GTO complex, both mandatory and optional, are considered. The authors of this article have developed and proposed at the scientific and methodological council of the Department of Physical Education recommendations to improve the situation with the implementation of the standard for endurance.
\end{abstract}

\section{Introduction}

The current state of the sphere of physical culture and sports is largely the result of the implementation of the Strategy for the development of physical culture and sports in the Russian Federation until 2020 (further - Strategy).

The strategy was adopted by the Government of the Russian Federation in 2009 in response to challenges related to deteriorating health of citizens, increasing global competition in sports and the development of modern technologies.

The systems of physical education and training of the sports reserve were significantly modernized. The material and technical base of physical culture and sports, personnel, scientific, scientific and methodological, medical, biomedical, and anti-doping support in elite sports have been developed.

The measures taken contributed to the spread of a positive attitude towards a healthy lifestyle among citizens.

In 2008-2019, within the framework of the implementation of the Strategy, the program and normative basis of the physical education system was formed and put into effect - the All-Russian physical culture and sports complex "Ready for Labor and Defense"(GTO).

The decree of the President of the Russian Federation "On the All-Russian physical culture and sports complex «Ready for work and defense (GTO)» dated March 24, 2014, No. 172 states that in order to further improve the state policy in the field of physical culture and sports, create an effective system of physical education aimed at developing human potential and strengthening the health of the population, from September 1, 2014,

\footnotetext{
* Corresponding author: olivka1103@yandex.ru
} 
the All-Russian physical culture and sports complex "Ready for Labor and Defense (GTO)» - is put into operation - the program and normative basis of physical education of the population [1].

The regulations on the All-Russian physical culture and sports complex "Ready for work and defense" indicate that the objectives of the GTO are to increase the efficiency of using the possibilities of physical culture and sports in strengthening health, harmonious and comprehensive development of the individual, fostering patriotism and ensuring continuity in the implementation of physical education of the population [2-3].

DSTU is doing a lot of work on the preparation and implementation of the new GTO complex. The main goal of the testing center is to assess the fulfillment by students of the requirements for the level of physical fitness when fulfilling the standards of the GTO complex, approved by order of the Ministry of Sports of the Russian Federation dated July 8, 2014 No. 575. [4]

The testing center, supervised by the rector of the DSTU B.Ch. Meskhi, in accordance with the tasks assigned to it, performs many functions, one of which is:

- carrying out propaganda and information work for students to form conscious needs in systematic physical culture and sports, physical improvement and maintaining a healthy lifestyle, popularizing participation in tests (tests) and standards of GTO complex.

What is the significance of the GTO complex at DSTU?

Firstly, it is intended to become the basis for the development of standards, programs for physical education and sports in DSTU, a physical culture and sports club, where physical training and sports work is carried out.

Secondly, the system of normative assessments of the GTO complex establishes the basic requirements of the state in the field of physical fitness of student youth.

Thirdly, the complex determines the list of basic knowledge, skills, and abilities of each student of the university in maintaining a healthy lifestyle, performing physical exercises, and playing sports.

The main tasks of the GTO complex at DSTU are:

- an increase in the number of students who systematically go in for physical culture and sports;

- formation of conscious needs among students in systematic physical culture and sports, physical improvement and healthy lifestyle;

- increasing the general level of students' knowledge about the means, methods and forms of organizing independent studies.

Systematic classes for the preparation and implementation of the standards of the GTO complex, for young students in physical education classes at DSTU, allow you to gradually join physical culture and sports, climb the steps of sportsmanship. The preparation of DSTU students to fulfill the standards and requirements of the GTO is based on the principles of voluntariness and availability, health-improving and personality-oriented orientation, and the compulsory medical control.

From the beginning of the founding of the GTO testing center of DSTU and up to the present time, the teachers of the Department of «Physical Education» of the Institute of Physical Education and Science of the DSTU have been conducting scientificmethodological and practical support of the GTO complex. Thanks to this, a lot of material has been collected and generalized. The data obtained are used in the development of programs for sports disciplines of the institute, in the preparation of proposals for effective preparation for the implementation of the GTO complex exercises. The main efforts of the department are aimed at improving the quality of physical fitness and increasing the number of people involved in physical culture and sports.

The development and support of the GTO complex allows you to solve many of the goals and objectives: 
1. Patriotic education of student youth

2. Harmonious development of personality

3. Motivation for a healthy lifestyle

4. Education of moral and volitional qualities

5. Psychological stability

6. Contribution to the National Health Program

The relevance of the research lies in the study of materials and the development of programs to improve work with student youth, introduction to a healthy lifestyle.

The expediency of this research lies in the search for new methods of influence on improving the quality of work with students in the field of physical culture and sports.

\section{Materials and methods}

The analysis includes data obtained as a result of fulfilling the standards of the GTO complex by students of our university. The peculiarities of the fulfillment of various standards included in the VI-th stage of the GTO complex, both mandatory and optional, are considered.

The age of student youth, in most cases, ranges from 18 to 24 years old. This age refers to the V-th stage of the GTO complex. Proceeding from this, the study was carried out at this stage.

The frequency of the survey is from February 2017 to February 2020, monthly, excluding the summer months.

The research was carried out by teachers of the Department of Physical Education.

The number of people under study is 200 monthly.

The total number of tested students is 5000 people.

Testing was carried out exclusively in competitive conditions.

The studied disciplines of the complex related to this stage: compulsory and optional.

Compulsory disciplines:

- running 30m, 60m, 100m (boys, girls)

- tilt (boys, girls)

- Pulling from a hang on a high bar (boys)

- Pulling from a hang on a low bar (girls)

- flexion / extension of the arms in the lying position (boys, girls)

- run $2000 \mathrm{~m}$ (girls)

- run $3000 \mathrm{~m}$ (boys).

Optional disciplines:

- shooting from electronic weapons (boys, girls)

- shuttle run $3 \times 10 \mathrm{~m}$ (boys, girls)

- lifting the torso in 1 minute (boys, girls)

- Long jump from a place (boys, girls)

- throwing a sports equipment (boys, girls)

- cross-country cross (boys, girls)

- swimming $50 \mathrm{~m}$ (boys, girls).

Data for the initial study was collected by the authors of the article between February 2017 and February 2018.

Table 1. Percentage of fulfillment of mandatory standards of the GTO complex by DSTU students as of February 2018.

\begin{tabular}{|c|c|c|c|}
\hline № & Types of tests & $\begin{array}{c}\text { Percentage of } \\
\text { completion (boys) }\end{array}$ & $\begin{array}{c}\text { Percentage of } \\
\text { completion (girls) }\end{array}$ \\
\hline 1 & $30,60,100 \mathrm{~m}$ & $78 \%$ & $64 \%$ \\
\hline
\end{tabular}




\begin{tabular}{|c|c|c|c|}
\hline 2 & Incline & $62 \%$ & $84 \%$ \\
\hline 3 & High bar pull-up & $72 \%$ & \\
\hline 4 & Hanging pull-up on a low bar & & $63 \%$ \\
\hline 5 & $\begin{array}{l}\text { Flexion / extension of the } \\
\text { arms in the lying position }\end{array}$ & $61 \%$ & $57 \%$ \\
\hline 6 & Run $2000 \mathrm{~m}$ & & $\begin{array}{c}26 \%(\text { did not reach } \\
21 \%)\end{array}$ \\
\hline 7 & Run $3000 \mathrm{~m}$ & $33 \%$ (did not reach $18 \%)$ & \\
\hline
\end{tabular}

Table 2. Percentage of compliance with the standards of the GTO complex at choice DSTU students as of February 2018.

\begin{tabular}{|c|c|c|c|}
\hline № & Types of tests & $\begin{array}{c}\text { Percentage of } \\
\text { completion (boys) }\end{array}$ & $\begin{array}{c}\text { Percentage of completion } \\
\text { (girls) }\end{array}$ \\
\hline 1 & Shooting & $58 \%$ & $52 \%$ \\
\hline 2 & Shuttle run 3x10 m & $76 \%$ & $64 \%$ \\
\hline 3 & Torso elevation & $82 \%$ & $89 \%$ \\
\hline 4 & Standing jump & $81 \%$ & $69 \%$ \\
\hline 5 & Throwing sports equipment & $79 \%$ & $67 \%$ \\
\hline 6 & Cross-country cross-country & & $31 \%(8 \%$ did not reach) \\
\hline 7 & Cross-country cross 5000 m & $41 \%(6 \%$ did not reach) & \\
\hline 8 & Swimming $50 \mathrm{~m}$ & $88 \%$ & $78 \%$ \\
\hline
\end{tabular}

Thus, the accumulated data allow us to make the following conclusion:

The results of the fulfilled standards indicate that such quality as endurance (running at $2000 \mathrm{~m}, 3000 \mathrm{~m}, 5000 \mathrm{~m}$ ) among students is at a very low level and, as a result, do not allow to perform the entire GTO complex as a whole. This is the only standard where there is a percentage of students who have not covered the entire distance.

The data obtained allow us to draw appropriate conclusions and make adjustments to physical culture classes with students. 


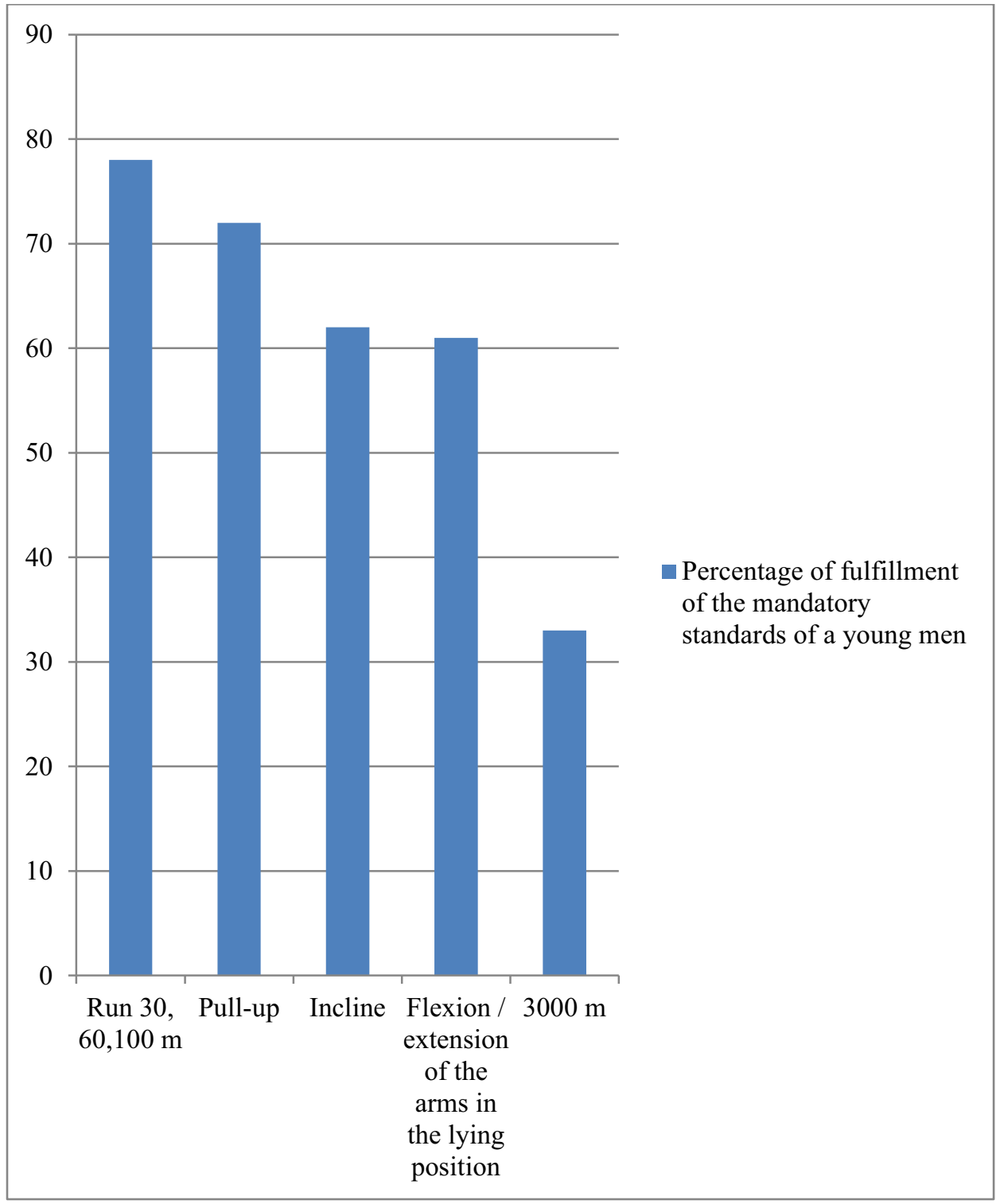

Fig. 1. Percentage of fulfillment of mandatory standards of the GTO complex among young men in 2018 


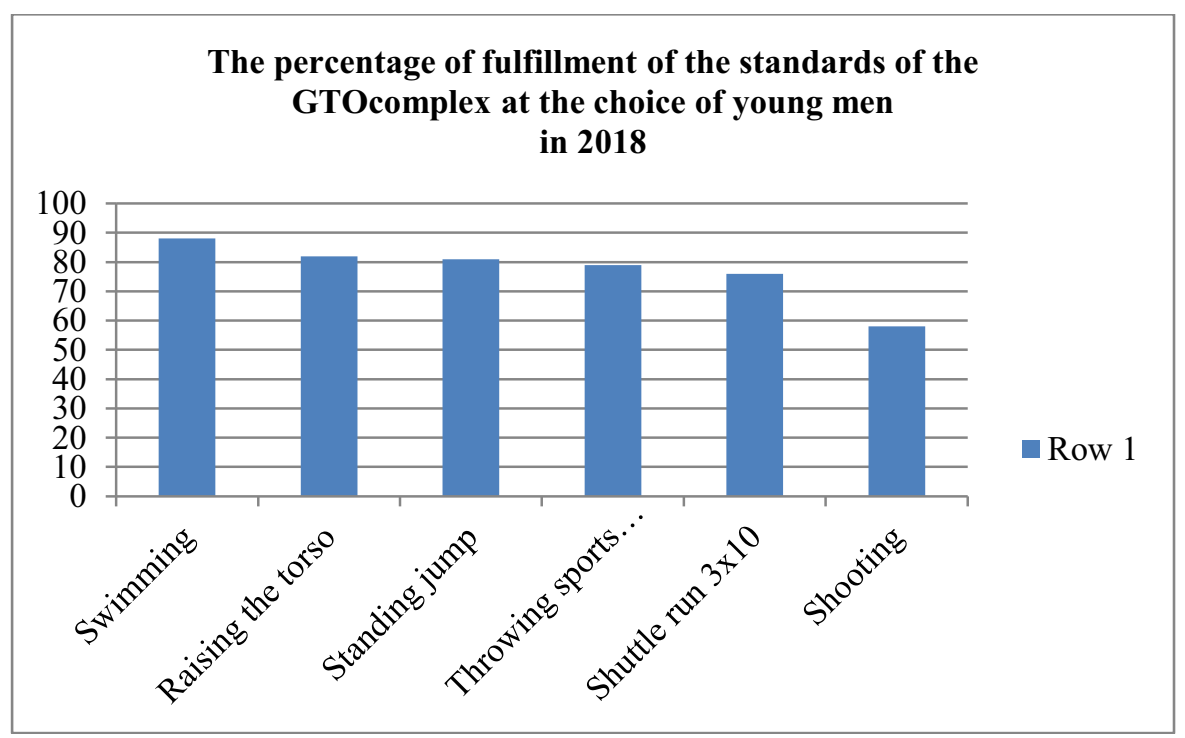

Fig. 2. The percentage of fulfillment of the standards of the GTO complex at the choice of young men in 2018

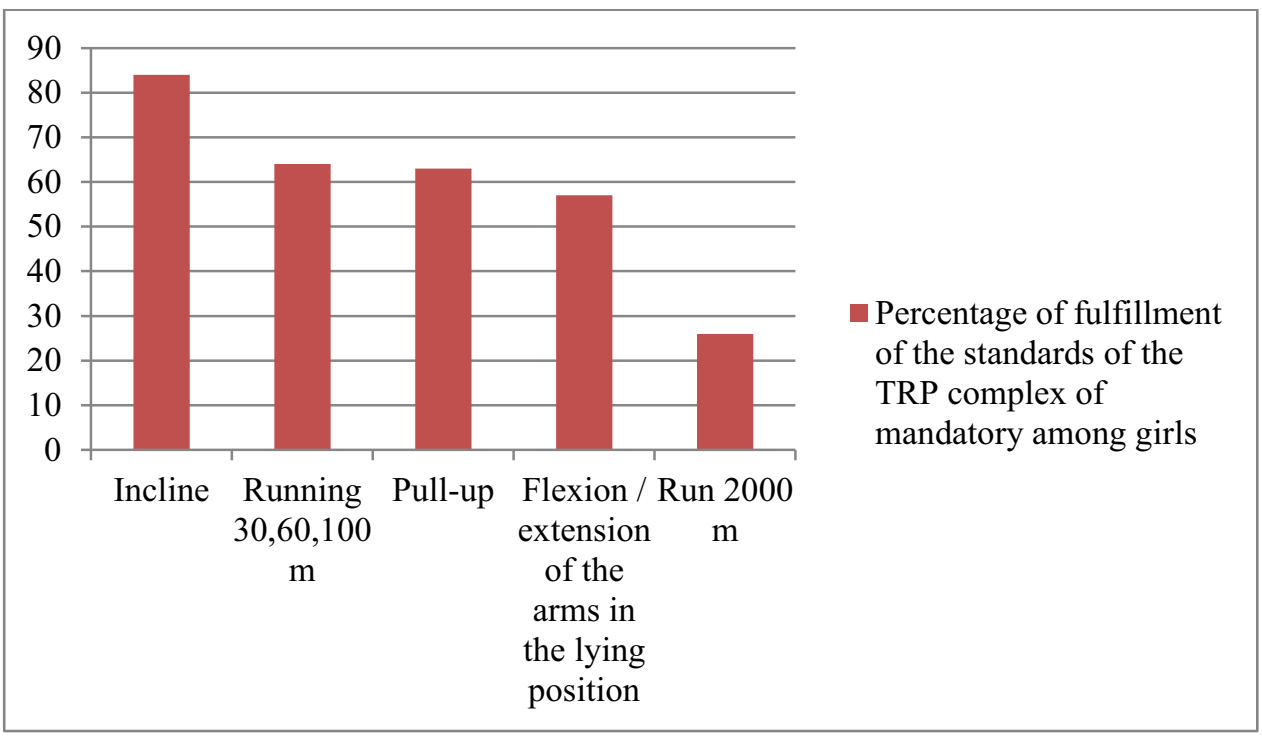

Fig. 3. Percentage of fulfillment of mandatory standards of the GTO complex among girls in 2018 


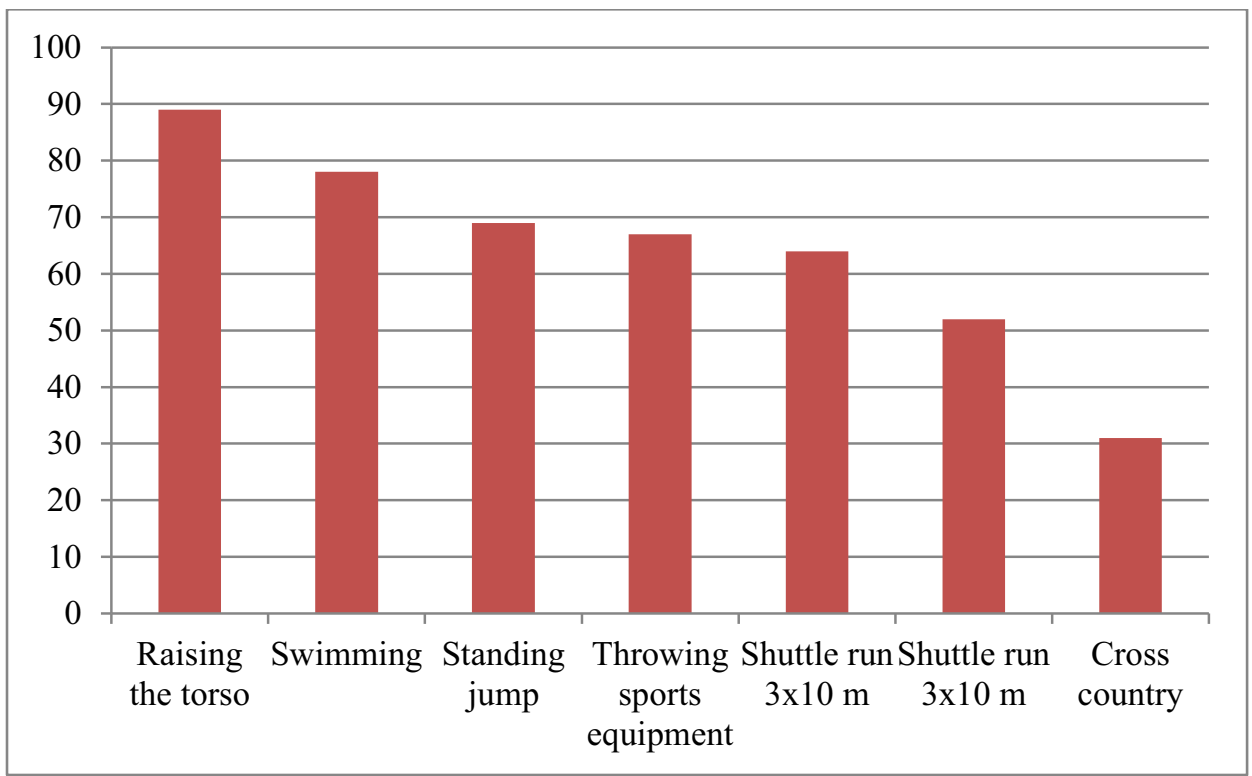

Fig. 4. Percentage of fulfillment of the standards of the GTO complex of choice among girls in 2018

The authors of this article have developed and proposed at the scientific and methodological council of the Department of Physical Education recommendations to improve the situation with the implementation of the standard for endurance.

It was suggested to pay attention to the development of the quality of endurance not only in the main physical culture lesson, but also in the "Optional course" lessons with elements of volleyball, football, swimming, rhythmic gymnastics, including exercises for general and special endurance, adjusting them for this specialization. Thus, bringing up this quality based on the sport chosen by the students.

The developed set of measures includes several stages.

At the initial stage, it is advisable to educate general endurance. Exercises are aerobic. For this, the following means and methods were used:

1. Optimal combination of endurance and breathing exercises.

2. Full oxygen saturation during the exercise (the well-developed material base of DSTU allows this).

3. Building endurance through precisely dosed exercise:

- running at various distances, varying the speed and intervals of rest;

-exercises for strength, flexibility, dexterity, organized in the form of a "circuit training".

The next stage is work in a mixed mode - aerobic-anaerobic. The intensity of the load increases, the rest intervals are shortened, the number of repetitions increases.

At the next stage, the exercises are performed in an aerobic-anaerobic mode and anaerobic. The exercises are performed in a competitive mode. Relays are added, fulfillment of control standards with a group of rivals.

At all three stages of classes, the teacher should remember about the individual approach to the students. The proposed load should correspond to the capabilities and physical condition of the students.

The authors of the article developed and recommended to students a program of additional independent studies outside school hours, aimed at increasing general and special endurance. Control over the implementation of independent studies was carried out by the authors of the article through remote communication with students. Also, students studying on their own were asked to keep a diary and adjust classes according to their well-being. 
The analysis of the fulfillment of the standards was carried out throughout the entire study period. The next control analysis of the fulfillment of the standards in February 2020 showed the effectiveness of the changes introduced by the authors to the structure of physical culture lessons regarding the fulfillment of the standard for endurance. The first positive aspect of the proposed innovative changes was that more students were able to cover the distance completely. For girls, $14 \%$ of the subjects could not overcome the distance of $2000 \mathrm{~m}$, for boys, $9 \%$ of the subjects could not overcome the distance of 3000 m. In cross-country cross-country these indicators also improved: for girls, $3 \%$ could not overcome the distance, for boys, $2 \%$. These students did not fulfill the standard, but they were able to cover the distance completely. The average time of passing the distance has improved (tables 3, 4).

Table 3. Data at the beginning of the experiment (2018)

\begin{tabular}{|c|c|c|c|c|c|c|}
\hline № & Distance & Completed & Got off & Best time & $\begin{array}{c}\text { Worst } \\
\text { time }\end{array}$ & $\begin{array}{c}\text { Average } \\
\text { time }\end{array}$ \\
\hline 1 & $2000 \mathrm{~m}$ (girls) & $26 \%$ & $21 \%$ & $7.23,18$ & $14.38,21$ & $11.50,05$ \\
\hline 2 & $3000 \mathrm{~m}$ (boys) & $33 \%$ & $18 \%$ & $10.17,42$ & $18.44,11$ & $14.50,04$ \\
\hline 3 & $\begin{array}{c}3000 \mathrm{~m} \text { cross on } \\
\mathrm{p} / \mathrm{m} \text { (girls) }\end{array}$ & $31 \%$ & $8 \%$ & $12.29,10$ & $21.16,44$ & $17.01,00$ \\
\hline 4 & $\begin{array}{c}5000 \mathrm{~m} \text { running } \\
\text { cross (boys) }\end{array}$ & $41 \%$ & $6 \%$ & $18.29,20$ & $31.14,52$ & $25.12,03$ \\
\hline
\end{tabular}

Note: best times are shown by sports students.

Table 4. End of experiment data (2020)

\begin{tabular}{|c|c|c|c|c|c|c|}
\hline № & Distance & Completed & Got off & Best time & $\begin{array}{c}\text { Worst } \\
\text { time }\end{array}$ & $\begin{array}{c}\text { Average } \\
\text { time }\end{array}$ \\
\hline 1 & $2000 \mathrm{~m}$ (girls) & $42 \%$ & $14 \%$ & $7.21,20$ & $13.49,18$ & $10.35,02$ \\
\hline 2 & $3000 \mathrm{~m}$ (boys) & $51 \%$ & $9 \%$ & $10.01,30$ & $16.54,27$ & $13.50,03$ \\
\hline 3 & $\begin{array}{c}3000 \mathrm{~m} \text { cross on } \\
\mathrm{p} / \mathrm{m} \text { (girls) }\end{array}$ & $49 \%$ & $3 \%$ & $12.11,42$ & $20.14,11$ & $16.12,05$ \\
\hline 4 & $\begin{array}{c}5000 \mathrm{~m} \text { running } \\
\text { cross (boys) }\end{array}$ & $62 \%$ & $2 \%$ & $17.49,13$ & $27.12,39$ & $22.50,08$ \\
\hline
\end{tabular}

Note: best times are shown by sports students.

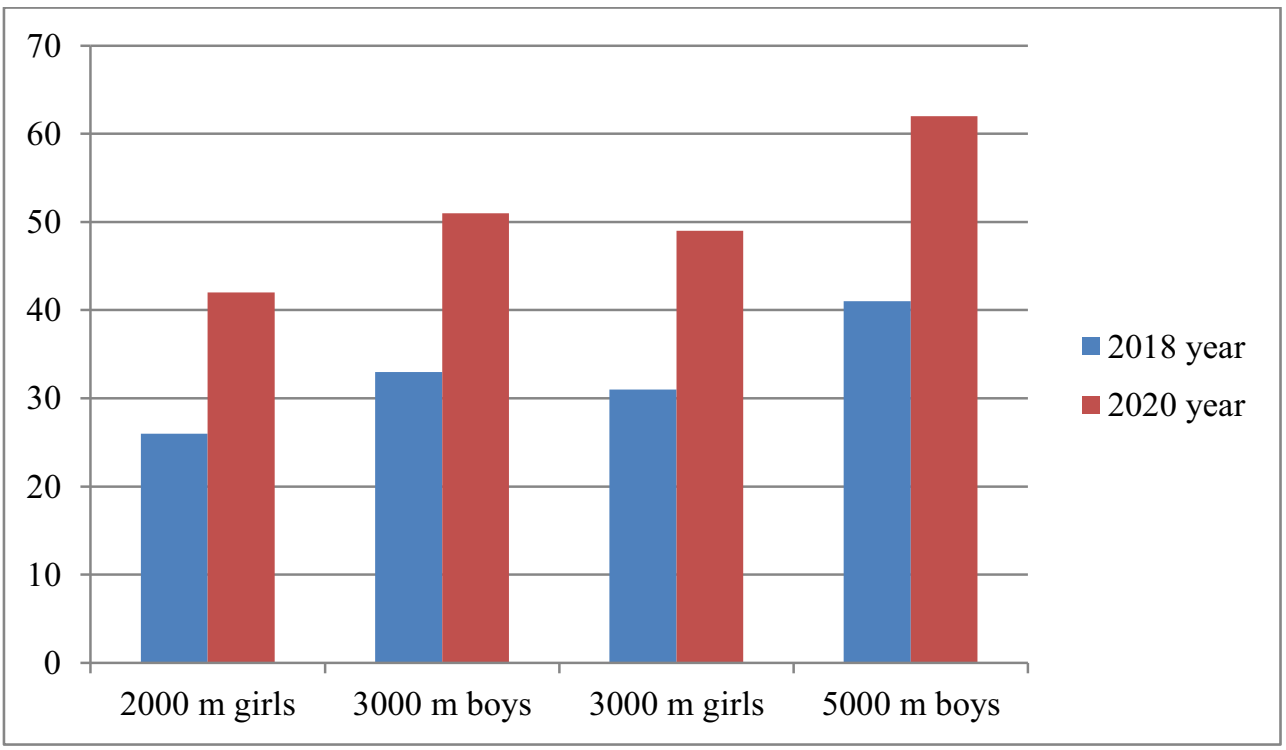


Fig. 5. The number of students who covered the distance (\%)

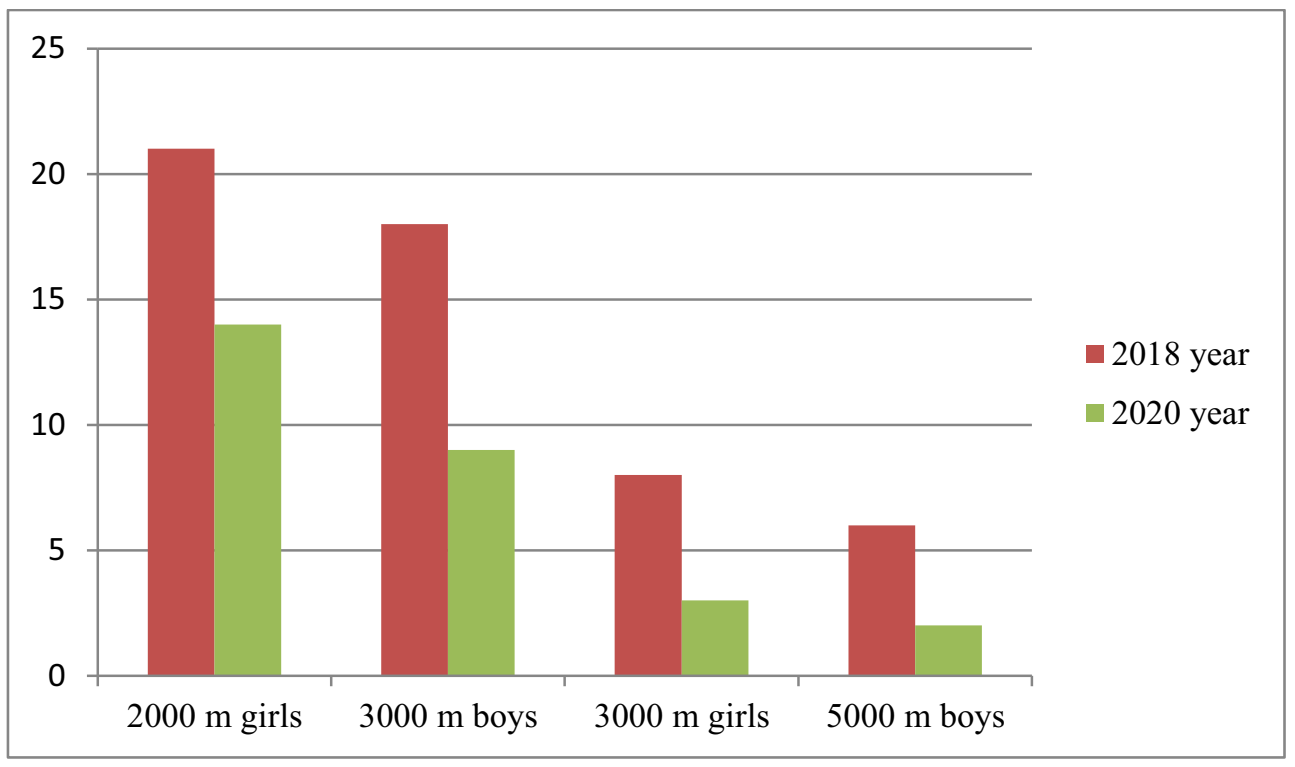

Fig. 6. The number of students who did not cover the distance (\%)

The time spent on overcoming the distance has decreased. Therefore, the authors of the article have chosen the right direction, which must be developed and improved by all means. In the future, adjustments will be introduced that were developed by the authors of the article during the study, the work will be continued, not only in the direction of developing endurance, but also according to other standards of the complex.

\section{Results}

More students were able to cover the distance completely, the time spent on covering the distance decreased, the average time to cover the distance improved.

\section{Discussions}

At the scientific and methodological council of the Department of Physical Education, the general decision of the council approved the direction chosen by the authors of this article, which must be developed and improved. The adjustments developed during the study will be introduced.

\section{Conclusions}

The presented brief summary of data on the critical problems of fulfilling the standard of the GTO complex - endurance by boys and girls of the VI stage, considered the reasons for the need for special attention to this problem and the introduction of new methods of training student youth to fulfill the standards of the GTO complex. This article can be useful to everyone who is interested in the current state of affairs in the field of physical culture and sports, in particular, the adoption of the standards of the GTO complex. 
The authors of the article express their gratitude to the rector of the DSTU B.Ch. Meskhi for the opening and supervision of the GTO Testing Center at the DSTU, which is so important for students, the director of the Institute of Physical Culture and Sports, Mavropulo O.S. for valuable advice in planning the study and recommendations for the design of the article, director of the GTO Testing Center at DSTU Pogona Yulia Vladimirovna for the assistance provided during the study.

\section{References}

1. E.V. Khromin, All-Russian physical education and sport GTO complex: municipal management innovations. Theory and Practice of Physical Culture 1, 3-5 (2019)

2. A.V. Voronkov, Academic physical fitness rating by GTO complex tests, ed. A.V. Voronkov, I.N. Nikulin, A.A. Kolesnikov, D.E. Nikulina, Theory and Practice of Physical Culture 5, 11 (2019)

3. T.J. Kauh, Building a culture of health through research: The role of the physical activity research center. Preventive Medicine 130, 105894 (2020)

4. S.G. Farris, Development and initial validation of the Exercise Sensitivity Questionnaire, Mental Health and Physical Activity 19, 100346 (2020)

5. P.S. Tandon, Short term impact of physical activity vs. sedentary behavior on preschoolers' cognitive. Mental Health and Physical Activity 15, 17-21 (2018)

6. A. Ivanova. Mathematical analysis of individual physical fitness test rates and functionality forecasts. Physical education: education, training 2(79), 53-56 (2019)

7. A. Ivanova, Adaptation and development of the physical culture and sports complex of the GTO in accordance with changes in society. In the collection: Innovative transformations in the field of physical culture, sports and tourism. Collection of materials of the XXI All-Russian scientific and practical conference 287-292 (2018)

8. P.S. Tandon, Short term impact of physical activity vs. sedentary behavior on preschoolers' cognitive functions. Mental Health and Physical Activity 15, 17-21 (2018)

9. S. Rahimi, Long-term exercise from adolescence to adulthood reduces anxiety- and depression-like behaviors following maternal immune activation in offspring. Physiology \& Behavior, 226, 113130 (2020)

10. T. Stepanova, Physical education and sports sector progress in rostov region. Theory and practice of physical culture 8, 98-99 (2018)

11. J.E. Simon, Health-related quality of life is decreased in middle-aged adults with chronic ankle instability. Journal of Science and Medicine in Sport 21(12), 1206-1209 (2018)

12. T. Wisbey-Roth, Prescribing exercise like the medicine it is. Journal of Science and Medicine in Sport 22(1), 1 (2019)

13. B.S. Frank, Movement profile influences systemic stress and biomechanical resilience to high training load exposure. Journal of Science and Medicine in Sport 22(1), 29-34 (2019)

14. J. Luke Pryor, Intermittent exercise-heat exposures and intense physical activity sustain heat acclimation adaptations. Journal of Science and Medicine in Sport 22(1), 117-122 (2019)

15. M. Shestakov, Content and ways of improving the physical education of students mastering management specialties. Scientific notes of the University. P.F. Lesgaft. 5(147), 199-203 (2017) 